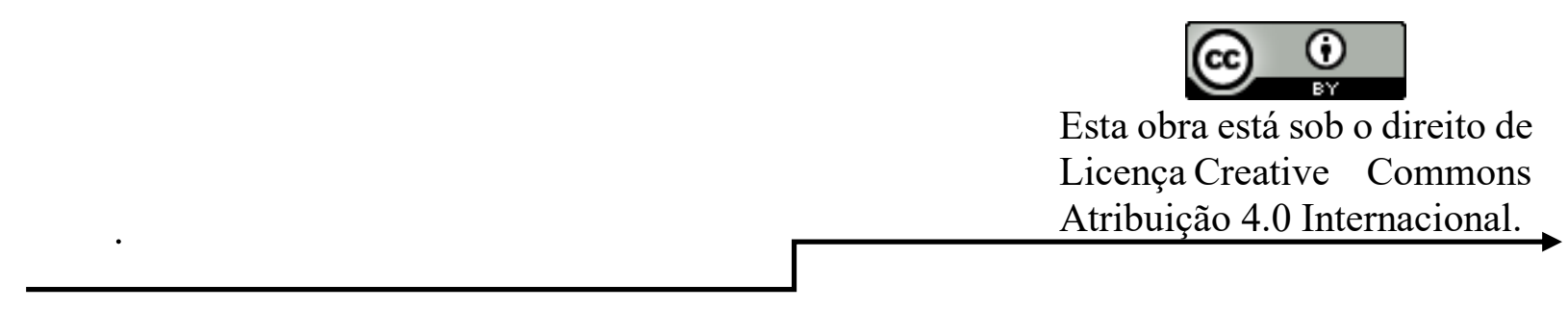

\title{
PROCESSO DE ENSINO E APRENDIZAGEM EM CRIANÇAS COM AUTISMO SEVERO: Uma Revisão Sistemática da Literatura
}

\author{
Aracy Felix Silva ${ }^{1}$ \\ Tânia Bechara Asfóra Galvão ${ }^{2}$
}

\section{RESUMO}

Esse artigo tem como objetivo abordar o percurso histórico acerca da pessoa com transtorno do espectro autista severo e a sua coordenação motora fina como processo de aprendizagem. A referida pesquisa é justificável pela importância de entender que a inclusão escolar é um processo que envolve o acesso, a permanência e o sucesso dos seus alunos, exigindo-nos os esforços necessários para nosso aperfeiçoamento no sentido de sua implementação. Trata-se de uma revisão sistemática da literatura, que visa identificar e selecionar as produções científicas acerca da aprendizagem do autista severo, com o intuito de sistematizar o conhecimento recente produzido acerca dessa temática e refletir sobre eles criticamente, indicando meios para apropriação e popularização dos recursos, técnicas e relações que beneficiam a aprendizagem do autista severo entre os profissionais da educação e a comunidade. Através desse estudo, pretendemos promover a reflexão sobre como incentivar e indicar meios para a efetividade do processo de ensino-aprendizagem do autista severo, esperamos, com isso, contribuir com a práxis educativa, partindo da premissa que a formação contínua dos profissionais é um elemento essencial para a expansão e a implementação da educação inclusiva que promove o desenvolvimento e a aprendizagem de todos os estudantes.

Palavras - Chave: Autismo Severo; Aprendizagem; Educação Inclusiva; Coordenação motora-fina;

\footnotetext{
1 aline_barros09_@hotmail.com

2 taniabechara@hotmail.com
} 


\section{INTRODUÇÃO}

O termo autismo origina-se do Grego autós, que significa "de si mesmo". É um Transtorno Global do Desenvolvimento (também chamado de Transtorno do Espectro Autista), caracterizado por alterações significativas na comunicação, na interação social, no comportamento da criança e falta de reciprocidade da parte afetiva. Essas alterações levam a importantes dificuldades adaptativas (ASSUMPÇÃO JR, et al., 2011).

O desenvolvimento de uma criança autista e sua aprendizagem tem que ser visto de forma mais cuidadosa, com uma preparação pedagógica voltada para este transtorno necessitando de um olhar específico. Sabe-se que há algumas décadas o autismo vem sendo estudado cientificamente no nosso país, o que pode dar margem a um diagnóstico que pode ser demorado, pois percorre alguns trajetos envolvendo o reconhecimento da família e uma equipe de múltiplos profissionais.

Diante disso, Mello (2007) afirma:

Autismo é uma síndrome definida por alterações presentes desde idades muito precoces, tipicamente antes dos três anos de idade, e que se caracteriza sempre por desvios qualitativos na comunicação, na interação social e no uso da imaginação. (MELLO, 2007, p. 16).

O Transtorno do Espectro Autista (TEA) infantil faz parte do grupo de pessoas com necessidades educacionais especiais. Para a inclusão ser uma realidade o mediador tem um papel fundamental no processo da avaliação, focando nas habilidades na qual a criança pode apresentar e assim buscando meios para melhor aprendizagem utilizando mecanismos como: jogos lúdicos, vídeos, músicas, brincadeiras educativas e outros.

A temática nos passa sinais importantes das necessidades de compreender o meio educacional que passa a ser um local de construção do conhecimento, melhorando a capacidade de aprender, utilizando estratégias para a sua evolução. Tendo como grande importância o apoio do núcleo familiar para obter bom êxito durante o processo.

Partindo do que foi discutido, nos indagamos quais os fatores que podem afetar o desenvolvimento e dificultar a aprendizagem da criança com Transtorno Espectro Autista (TEA) e, quais as dificuldades encontradas por crianças autistas severas, quando a sua coordenação motora fina apresenta déficits? Levando em consideração as dificuldades encontradas, o que pode ser feito para potencializar a 
aprendizagem e o desenvolvimento dessas crianças?

Partimos da hipótese de que o diagnóstico tardio do autismo é um dos pontos importantes a serem considerados, pois quando não é diagnosticado cedo o transtorno pode prejudicar a evolução da aprendizagem da criança em função das muitas dificuldades em sua socialização no meio que está inserida, tanto familiar, quanto escolar.

A família é tida como a instituição de socialização primária, sendo de suma importância para o desenvolvimento da vida da criança no seu dia-a-dia, orientando diante dos desafios e aprendizagens no cotidiano.

De acordo com a Lei 12.764 de 27 de dezembro de 2012, que institui os direitos da pessoa com transtorno do espectro autista, no seu artigo $3^{\circ}$ - Parágrafo único estabelece que: "Em casos de comprovada necessidade, a pessoa com transtorno do espectro autista incluída nas classes comuns de ensino regular, nos termos do inciso IV do art. $2^{\circ}$ terá direito a acompanhante especializado". Diante disso o indivíduo portador de autismo tem seus direitos garantidos com melhoramento para um aprendizado qualificado.

Para Vygotsky (1994), o entendimento da relação entre aprendizado e desenvolvimento ajudaria à aplicação correta das teorias educacionais. Nesse sentido, ele procurou confrontar as três principais teorias existente até então, enquanto preparava o terreno para colocação de suas ideias.

Em suma, a busca para poder, cada vez mais, qualificar a metodologia ou prática de ensino, proporcionando a essas crianças possibilidades de uma melhor e mais eficiente aprendizagem, já que estamos lidando com crianças autistas, de grau dado como severo que apresentam diversos prejuízos pela ineficiência da sua coordenação motora fina.

A utilização de ferramentas como o PECS, que é um sistema de comunicação por troca de figuras, a técnica do TEACCH que se baseia em princípios tais como: adaptação do ambiente às limitações da criança, elaboração de um plano de intervenção, trabalhando o lúdico, com músicas, leituras e brincadeiras. É uma forma de desenvolver e inserir a pessoa portadora de TEA, fazendo com que ela se sinta um ser social, interagindo com outras crianças. Levando em consideração as suas dificuldades de comunicação verbal e nãoverbal com o outro, tendo em vista os conflitos em suas compreensões.

Dentre as problemáticas que uma criança autista tem que enfrentar, a dificuldade na coordenação motora fina implica decisivamente no processo de ensino e aprendizagem, causando-lhe grande prejuízo, cabendo aos profissionais 
da área diversificarem suas metodologias, abrindo-lhe um leque de possibilidades para que assim, os prejuízos sejam minimizados e a aprendizagem seja favorecida.

Esta pesquisa tem como finalidade fazer um estudo do processo de aprendizagem da criança com autismo severo, buscando potencializar a atuação pedagógica e a aprendizagem da criança. Para tanto, será utilizada uma abordagem qualitativa para investigação do fenômeno, através da revisão sistemática da bibliografia, enfocando as contribuições científicas dos últimos 5 anos das áreas da Pedagogia, Psicologia e Psicopedagogia para o estudo do processo de aprendizagem da criança autista, enfocando o autismo severo e as dificuldades motoras finas associadas. Contribuindo, assim, com discussões e meios que favoreçam uma prática educativa consciente e adaptada às necessidades que o autismo severo impõe ao ensino-aprendizagem.

\section{O transtorno do espectro autista}

A palavra autismo atualmente pode ser associada a diversas síndromes. Os sintomas variam amplamente, o que explica por que atualmente refere-se ao autismo como um transtorno. O autismo manifestase de diferentes formas, variando do mais alto ao mais leve comprometimento, e dentro desse espectro o transtorno, que pode ser diagnosticado como autismo, pode também receber diversos outros nomes, concomitantemente.

O que se faz necessário ter em mente ao educador é que o autismo segundo (SURIAN, 2010) "aparece antes dos 3 anos de idade e permanece na vida adulta", assim na alfabetização os educadores estão sempre propensos a encontrarem um aluno autista em sala de aula e o educador precisa ter em mente que essa criança possui algumas capacidades específicas desenvolvidas de forma excepcional.

Se faz necessário dar suporte essencial para uma alfabetização de qualidade aos alunos autistas, inserindo todos, para não ter que ouvir nos meios de comunicações sociais o nome analfabeto direcionado a autistas e sim que a educação abrange a todos de forma geral, inserindo a leitura e a escrita, com a finalidade de ser cidadãos letrados e pessoas titulares em direito e forma própria de pensar e de ver o mundo.

As práticas pedagógicas direcionadas à alfabetização de autistas têm registrado avanços que buscam promover o desempenho da criança no processo de aquisição da leitura e da escrita, considerando-a um ser social, isso aconteceu a partir da inclusão, ou seja, ao nascer ela está inserida na escola, no universo da linguagem pelas imagens, cultura, grupo familiar, conhecimentos e pelas relações sociais. 
Ter como pressuposto, a criança autista enquanto ser social é destacar como concepção de aprendizagem a necessidade humana, pois anteriormente falando estes eram completamente desprezados e deixados de lado vistos como "loucos", pois a manifestação fundamental do autismo diz respeito à falta de interação social adequada à idade.

A preservação da vida está intrinsecamente ligada ao universo simbólico e aos conhecimentos que as pessoas adquirem durante sua vida. A criança inserida precisa além desses conhecimentos, desenvolver habilidades, competências, valores, hábitos e atitudes que permitirão a solução de problemas e o convívio social. Entende-se então que, a escola como instituição responsável pelo processo de interação social tem como prioridade a aprendizagem. $\mathrm{O}$ aprendizado escolar vem carregado de internacionalidades e deve priorizar os conhecimentos necessários à vida em sociedade.

Entende-se que alfabetizar é um processo lento e requer que o aluno construa esse conhecimento relacionando-o com a participação social, pois desde criança o homem se comunica por meio da linguagem, transmitindo suas ideias e pensamentos, acessando informações, produzindo conhecimento e ampliando sua visão do mundo, quando se trata de uma criança autista o processo de alfabetizar se torna além de lento, complexo. A língua é um sistema de signos históricos e sociais que possibilitam as pessoas darem melhor significados ao mundo e a realidade. Por isso ao aprendê-la é preciso entender suas significações e para a criança autista esse aprendizado é muito lento e muitas vezes regressivo.

De acordo com o Congresso Nacional, no que diz respeito à educação, a legislação 12.764, de 27 de dezembro de 2012 que institui uma Política Nacional de Proteção dos Direitos da Pessoa com Transtorno do Espectro Autista, garante perante o Art. 2o, Parágrafo VII - “o incentivo à formação e à capacitação de profissionais especializados no atendimento à pessoa com transtorno do espectro autista, bem como a pais e responsáveis". O Art. $3^{\circ}$, parágrafo IV - que "todo autista tem direito à educação e ao ensino profissionalizante".

Entre os fatores destacados, é válido destacar que o autista também pode desenvolver medos intensos que desencadeiem fobias, assim o aluno poderá desencadeá-las na escola, e essa fobia pode ser ao educador ou qualquer outro profissional da instituição escolar.

\section{Educação Inclusiva}

O processo de inclusão escolar consiste na igualdade dos direitos e deveres dos alunos, uma vez que esse será inserido 
em instituições de ensino regular, para participar de um processo de aprendizagem de maneira que, independa que os alunos tenham ou não algum tipo de deficiência respeitando as diferenças de cada um deles, por um determinado período (CARDOZO, 2003).

$\mathrm{Na}$ inclusão é primordial um trabalho junto às crianças ditas "normais" e aos seus familiares, em uma tentativa de promover um clima de aceitação incondicional da diferença que acarretaria na dissolução das desigualdades, essa forma de metodologia se faz necessária em alguns casos (SANTOS, 2009).

$\mathrm{Na}$ escola regular, a convivência do aluno especial com os demais alunos ouvintes, e professores, pais, comunidade na qual o aluno vive, lhe dará bases para uma boa integração a coletividade. Uma vez que, o atendimento e a formação desses profissionais sejam habilitados e preparados e os demais alunos também possam receber orientação sobre a deficiência do colega de sala, pois se sabe que um aluno especial pode falar mais alto que o normal e não perceber e os demais alunos precisam entender isso e saber que aos poucos aconteceram mudanças nessa dificuldade, entre outras que podem surgir.

A escola deve promover o desenvolvimento físico, cognitivo, afetivo, moral $\mathrm{e}$ social dos alunos com necessidades educativas especiais, e ao mesmo tempo facilitar-lhes a integração na sociedade como membros ativos. Mas para que isto aconteça, é importante que o indivíduo portador de necessidades educativas especiais seja visto como um sujeito eficiente, capaz, produtivo, e, principalmente, apto a aprender a aprender (GOFFREDO, 1999, p.32).

Uma vez que, a maioria dos alunos no âmbito escolares são ouvintes, natural que o aluno especial se junte aos seus amigos de forma a ser igual, mas certo de sua dificuldade. Cabe aos profissionais da área de educação especial buscar trabalhar com os demais alunos a língua de sinais, unificar o método de ensino e aprendizagem de educação comum e especial, para que possa ter uma maior diversidade de conhecimento e aprendizado, consequentemente um melhor processo de integração social e escolar. O aprendizado, portanto, não deveria ser focalizado numa área apenas, ao contrário, ele precisa proporcionar a aquisição de diversas capacidades particulares. Uma disciplina só afetaria e contribuiria para o desenvolvimento de uma outra à medida que tivesse algum ponto em comum entre elas (VYGOTSKY, 1994).

A Inclusão constitui-se num processo à medida que necessita ser avaliada e reforçada numa luta permanente 
contra as estratégias manobras de exclusão social. Nesse sentido, as pessoas devem ser percebidas com igualdade, implicando assim no reconhecimento e atendimento de suas necessidades especiais frente a esse novo paradigma educacional (CARDOZO, 2003).

A resistência ocorre tanto com os professores do ensino dos anos iniciais regular ao se depararem com o número elevado de alunos por turma, com a estrutura física inadequada, o despreparo para ensinar alunos surdos ou com outros problemas que façam com que esse seja especial, as péssimas condições de trabalho e os limites da formação profissional. Outro ponto a ser observado são os professores da educação especial que também não se sentem preparados para trabalhar com a diversidade do alunado e complexidade e amplitude dos processos de ensino dos anos iniciais e aprendizagem.

Segundo (MANTOAN, 2003):

Tanto a escola comum como a escola especial têm resistido às mudanças exigidas por uma abertura incondicional às diferenças. Uma das mais sérias e influentes razões para que essa situação se mantenha é a neutralização dos desafios que a inclusão impõe ao ensino dos anos iniciais comum e que mobilizam o professor a rever e a recriar suas práticas e a entender as novas possibilidades educativas trazidas pela escola para todas

(MANTOAN, 2003, p.12).

Atualmente, observam-se em muitas escolas várias ações democráticas, procurando garantir o acesso a todos, sem nenhuma forma de distinção ou discriminação. Uma educação voltada para a diversidade. Na verdade, o acesso é garantido regulamentado em leis. Já a educação, que vem sendo praticada em favor da inclusão educacional tem suas deficiências e precisam ser trabalhadas em busca de melhorias.

\section{O processo de ensino e aprendizagem}

Atualmente o autismo vem sendo bem mais divulgado, o número de casos diagnosticados vem crescendo e acontecendo em idades cada vez mais precoces, porém ele ainda surpreende, devido à diversidade de sintomas que pode apresentar.

Segundo Nogueira (2007): 
No entanto o autismo vem com um diagnóstico de transtornos que prejudica o indivíduo dificultando a sua aprendizagem e desenvolvimento e com dificuldades de interagir com os demais em seu meio social.

A observação é extremamente relevante na avaliação do grau de autismo. $\mathrm{Na}$ escola, deve-se utilizar o afeto e atentar para os estímulos peculiares do autista para conduzi-lo ao aprendizado, porque na educação quem mostra o caminho é quem aprende e não quem ensina. (CUNHA, 2012).

Diante disso a escola deve mostrar mecanismos que incentiva o indivíduo para um melhoramento de seu desempenho, descobrindo assim através de atividades avaliativa a evolução do aluno.

[...] O primeiro passo do professor deverá ser o de desenvolver a capacidade de concentração na criança, pois o que mais impede o seu aprendizado é ausência de atenção ao comando. É claro que os estágios de aprendizagem de qualquer aluno não obedecem a regras fixas, principalmente na realidade do autismo, o professor deverá contar com sua sensibilidade para conduzir todo o processo [...] (CUNHA, 2012).

Como explicita a Lei 12.764 (27 de dezembro de 2012) que a criança autista tem que ser integrada a um sistema educativo regular, garantindo recursos que atendam suas necessidades especiais.

O autista deve ser incluído em sala de aulas normais de ensino para que exista uma socialização entre eles e os demais colegas. Garantindo assim troca de ideias existindo respeito e tolerância das diferenças, tornando um processo de aprendizagem inclusiva.

Mittler (2003) afirma que:

\begin{abstract}
A inclusão tem como intuito garantir que todas as crianças façam parte de um grupo, comunidade, e de um sistema de ensino que possa oferecer oportunidades, assim como as demais crianças que não possuem nenhuma necessidade especial, na tentativa que essas crianças sejam inclusas e escapem dos preconceitos e isolamento. (MITTLER, 2003, p.32).
\end{abstract}

Um atendimento especializado, antes da inclusão numa escola regular, pode ajudar a criança a desenvolver a consciência de si mesma, preparando-a para utilizar-se de modelos, posteriormente. (MELLO, 2007).

De acordo com Cunha (2010) a criança depende dos familiares, enquanto membros sociais mais competentes e provedores de cuidados básicos necessários à satisfação de suas necessidades, exercendo uma enorme influência no 
desenvolvimento e crescimento dessa criança. Pois a família e a primeira sociedade a qual ele está inserido.

E de grande relevância a participação educacional e compreensão com a criança com autismo dando-lhe suportes e sustentabilidades especiais para obter um bom desenvolvimento ao decorrer da sua aprendizagem a utilização do brincar, com jogos concretos, materiais lúdicos, músicas e outros com um auxílio de um mediador avaliando assim sua evolução.

Existem graus de dificuldades no processo da aprendizagem com crianças autistas, visto os graus existentes. Tem o nível I (grau leve) menor necessidade de apoio, sendo que ele deverá ser baseado em ajudar na dificuldade em se manter uma comunicação social. A criança, nesse grau apresenta também dificuldade em iniciar interações com as demais pessoas, bem como pouco interesse em se relacionar com os demais. Há ainda um padrão de comportamento repetitivo e restrito, acarretando uma inflexibilidade comportamental e hiperfoco.

\section{METODOLOGIA}

A presente pesquisa trata-se de uma Revisão Bibliográfica da Literatura do tipo Revisão Sistemática (RS) de abordagem qualitativa e descritiva. Segundo Sampaio e
Nível II (moderado) requer o apoio de forma é mais substancial, sendo que há um déficit mais evidente nas habilidades de comunicação verbal e não-verbal. Há ainda prejuízos por falta de interação social com outras pessoas. Há uma resistência também diante de mudanças na rotina, algo que pode ser facilmente percebido pelos familiares. A criança também pode se estressar com maior recorrência e ter dificuldade em manter o foco em diversas atividades.

Nível III (severo) dificuldade de lidar com mudanças na rotina, e os comportamentos restritos/repetitivos interferem bastante no cotidiano.

O apoio é muito substancial nesse nível de intensidade do autismo, sendo que há severos prejuízos acerca da sua comunicação verbal e não-verbal. As limitações acerca de qualquer interação são uma evidência marcante, assim como uma forte presença de inflexibilidade comportamental. Outro ponto importante diz respeito ao elevado grau de estresse que a criança pode apresentar, em contar uma forte resistência para mudar sua atividade ou foco.

Mancini (2007) uma revisão sistemática da literatura tem como pressupostos a busca de fontes na literatura científica sobre a investigação de uma determinada temática, contemplando evidências de obras disponíveis através de métodos explícitos e 
sistematizados na busca de dados, dos quais visam analisar o estudo e sintetizar as informações apresentadas.

De acordo com Brasil (2012) esse método de estudo é classificado como confiável e rigoroso nos seus procedimentos metodológicos. Pois permite reunir, integrar e interpretar criticamente os resultados e evidências de diversos estudos científicos, dos quais podem revelar dados conflitantes e/ou convincentes, como também, identificar a necessidade de novas pesquisas na área do conhecimento ou fenômeno de interesse;

Para Sampaio e Mancini (2007), a Revisão Sistemática tem como passo (quadro 1): 1. Definição da pergunta; 2. Busca da evidencia; 3. Revisão e seleção dos estudos; 4. Análise da qualidade metodológica e 5 Apresentação dos resultados.

Quadro 1. Passos da Revisão Sistemática.

\begin{tabular}{|l|lr|}
\hline \multicolumn{1}{|c|}{ Passos } & \multicolumn{2}{|c|}{ Descrição } \\
\hline $\begin{array}{l}\text { 1. Definição } \\
\text { da pergunta }\end{array}$ & $\begin{array}{l}\text { A RS requer uma } \\
\text { pergunta ou questão } \\
\text { bem formulada e clara } \\
\text { para a investigação na } \\
\text { literatura. }\end{array}$ \\
\hline $\begin{array}{l}\text { 2. Busca da } \\
\text { evidencia }\end{array}$ & $\begin{array}{l}\text { Inicia-se com a } \\
\text { definição do termo ou } \\
\text { palavras-chave, } \\
\text { consecutivamente da } \\
\text { seleção das bases de } \\
\text { pesquisa, estabelecendo } \\
\text { os critérios do estudo. }\end{array}$ \\
\hline
\end{tabular}

\begin{tabular}{|l|l|}
\hline $\begin{array}{l}\text { 3. Revisão e } \\
\text { seleção dos } \\
\text { estudos }\end{array}$ & $\begin{array}{l}\text { Avalia-se inicialmente } \\
\text { os títulos e resumos } \\
\text { (abstracts), para compor } \\
\text { a amostra da pesquisa. }\end{array}$ \\
\hline $\begin{array}{l}\text { 4. Análise da } \\
\text { qualidade } \\
\text { metodológica }\end{array}$ & $\begin{array}{l}\text { Investiga } \\
\text { instrumentos e as etapas } \\
\text { metodológicas } \\
\text { utilizadas nos estudos, } \\
\text { como também, a } \\
\text { relevância e qualidade. }\end{array}$ \\
\hline $\begin{array}{l}\text { 5. } \\
\text { dosresentação } \\
\text { resultados }\end{array}$ & $\begin{array}{l}\text { Apresenta uma síntese } \\
\text { dos resultados positivos } \\
\text { e negativos dos estudos, } \\
\text { trazendo perspectivas. }\end{array}$ \\
\hline
\end{tabular}

Fonte: SAMPAIO; MANCINI, 2007.

No Quadro 1 é estabelecido os procedimentos que nortearão essa Revisão Sistemática. Assim, a pesquisa será realizada por meio das palavras-chave: Autismo severo; Processo de aprendizagem; Educação inclusiva, através de diferentes combinações, utilizando o operador booleano “AND”. Tendo como os bancos de dados selecionados: Scientific Electronic Library Online (SciELO); Medical Literature Analysis and Retrieval System Online (MEDLINE); Periódicos Eletrônicos de Psicologia (PePSIC) e Portal de Periódicos CAPES.

Os critérios dessa pesquisa, são subdivididos em dois grupos, sendo eles, 1) critérios de inclusão e 2) critérios de exclusão. Os critérios de inclusão definidos são artigos científicos inéditos; artigos publicados gratuitamente; artigos com os textos completos na íntegra online; artigos nos idiomas em português e espanhol; 
artigos que possuam uma ou mais das palavras-chave; artigos publicados entre os anos de 2014 a 2019. E os critérios de exclusão: Teses, dissertações de mestrado; artigos duplicados; artigos irrelevantes para os objetivos da pesquisa.

Posteriormente, os estudos serão avaliados pelos títulos e resumos (abstracts), dos quais constituirão a amostra da pesquisa. Para a análise do rigor metodológico dos artigos selecionados como relevantes ao estudo serão

\section{RESULTADOS E DISCUSSÃO}

O principal resultado será o levantamento de dados e informações relevantes a profissionais da área que proporcione a reflexão e conscientização sobre o processo de aprendizagem da criança autista, favorecendo também o suporte para os mediadores elaborarem

\section{CONCLUSÃO}

O presente artigo possibilita compreender do autista e as contribuições do escolar. Desse modo, esta pesquisa sugere uma compreensão de como a criança com autismo é inserida no âmbito escolar, assim, observa-se a importância das intervenções psicológicas no contexto atendimento educacional especializado frente à aprendizagem do aluno com autismo. observados: 1) Os objetivos do estudo foram definidos com precisão? 2) A metodologia utilizada é adequada para atingir esses objetivos? 3) A fundamentação dos argumentos é coerente, coesa e bem referenciada? 4) Há uma descrição eficiente dos procedimentos utilizados? 5) Os objetivos do estudo foram alcançados?

Após a avaliação da qualidade e relevância dos estudos, os resultados serão sintetizados e descritos na discussão do trabalho.

atividades atrativas que possam superar as limitações na coordenação motora fina apresentadas pelas crianças com um grau severo de autismo e favorecer a sua aprendizagem a nível integral e significativo, potencializando, com isso, seu desenvolvimento.

Essa análise implica como necessária a garantia de intervenções de aprendizagem mais direcionadas no ambiente educacional, uma vez que evidencia no aluno com autismo benefícios cognitivos e sociais. As salas multifuncionais de referência, que é um espaço organizado com materiais didáticos, equipamentos e profissionais capacitados, que podem atender às necessidades educacionais especiais dos alunos, para 
fornecer suporte necessário e facilitador do acesso ao conhecimento.

Os desiguais e complexos aspectos que permeiam o método de inclusão escolar de alunos com autismo podem ser

\section{REFERÊNCIAS}

ASSUMPÇÃO JR, Francisco B, KUCZYNSKI, Evelyn. Diagnóstico diferencial psiquiátrico no autismo infantil. Em: SCHWARTZMAN, José Salomão; ARAÚJO, Ceres Alves de. Transtornos do espectro do autismo. São Paulo: Memnon, 2011.

BRASIL, Lei $\mathrm{n}^{\circ}$ 12.764, de 27 de dezembro de 2012. Política Nacional de Proteção dos Direitos da Pessoa com Transtorno do Espectro Autista.

BRASIL. Diretrizes metodológicas: elaboração de revisão sistemática e metanálise de ensaios clínicos randomizados. Ministério da Saúde, Secretaria de Ciência, Tecnologia e Insumos Estratégicos, Departamento de Ciência e Tecnologia. 1 ed. Brasília: Editora do Ministério da Saúde, 2012. 96 p.

BELO, L. R. et al. Valores referenciais da eletromiografia de músculos envolvidos na deglutição: uma revisão sistemática.

Revista CEFAC, v. 14, n. 1, 2011.

Disponivel em:

$<$ http://www.scielo.br/scielo.php?script $=$ sc i_arttext\&pid $=$ S1516-

18462012000100018>. Acesso em: $16 \mathrm{dez}$. 2019.

CUNHA, Eugenio. Autismo e inclusão: Psicopedagogia Práticas Educativas na Escola e na Família. 6. Ed. Rio de janeiro: Wak Ed, 2012. abordados numa expectativa teórica sólida, que auxilie na compreensão do desenvolvimento humano e de relações escolares inclusivas.

CUNHA, Eugênio. Autismo e inclusão: psicopedagogia e práticas educativas na escola e na família. Rio de Janeiro: Wak, 2010.

ESTRELA, C. Metodologia

Científica: Ciência, Ensino, Pesquisa. $3^{\mathrm{a}}$. ed. Porto Alegre: Artes Medicas, 2018. 725 p.

JADAD, A. R. et al. Assessing the Quality of Reports of

Randomized. semanticscholar, 1996.

Disponivel em:

$<$ https://pdfs.semanticscholar.org/8308/34c ccb0e42f08fd760e03ce3e8b54011edba.pdf >. Acesso em: 16 dez. 2019.

MELLO, Ana Maria S. Ros de. Autismo: guia prático. 5 ed. São Paulo: AMA. Brasília: CORDE, 2007.

MITTLER, P. Educação inclusiva. Contextos sociais. Porto Alegre: Artmed, 2003.]

NOGUEIRA, Tânia. Um novo olhar sobre o mundo oculto do autismo. Revista Época. São Paulo: Editora Globo, no 473, p. 76-85. junho, 2007.

SAMPAIO, R. F.; MANCINI; M. C.

Estudos de revisão sistemática: um guia para síntese criteriosa da evidência científica. Rev. bras.

Fisioter, v.11 n.1, 2007.

SURIAN, Luca. Autismo: informações essenciais para familiares, educadotes e profissionais da saúde. São Paulo: Paulinas, 2010. 
TOZONI-REIS, Marília Freitas de Campos. A pesquisa e a produção de conhecimentos: introdução à pesquisa em educação. Curso de pedagogia da Unesp. 2010. Disponível em: Acesso em: 10 out. 2019.
VYGOTSKY, L.S. "Interação entre Aprendizado e Desenvolvimento", in A Formação Social da Mente. São Paulo: Martins Fontes, 1994. 